\title{
ALTERNATIVAS DEL INTERVENCIONISMO ESTATAL EN LA AGROINDUSTRIA DEL AZÚCAR. ARGENTINA Y BRASIL, 1880-1938*
}

\section{ALTERNATIVES OF STATE INTERVENTIONISM IN THE SUGAR AGROINDUSTRY. ARGENTINA AND BRAZIL, 1880-1938}

\author{
Daniel Campi** \\ Universidad Nacional de Tucumán, Tucumán, Argentina, dcampi@ises.org.ar
}

\section{Heitor Pinto de Moura Filho}

Presidente da Associação Biblioteca de Cultura, Rio de Janeiro, Brasil, h.moura@uniconsult-rj.com.br

\section{María Celia Bravo**}

Universidad Nacional de Tucumán, Tucumán, Argentina, mceliabravo@hotmail.com

\begin{abstract}
Resumen. El texto propone un análisis comparativo de las diversas alternativas de intervención estatal en la agroindustria del azúcar que se implementaron en Brasil y Argentina a partir de la década de 1880. Crisis de sobreproducción, pérdida de competencia en el mercado internacional, conflictos entre diferentes actores y zonas productoras dieron origen a arreglos institucionales en los dos países que perseguían valorizar el producto, conciliar intereses y hacer previsible el comportamiento de un mercado siempre complejo. El análisis se cierra en 1937-1938 con la inauguración de la experiencia del Estado Novo en Brasil, que profundizó el intervencionismo, y el fracaso en Argentina de un intento de aprobar una ley que habría involucrado decisivamente al Estado en el desarrollo azucarero.
\end{abstract}

Palabras clave: Estado; agroindustria azucarera; Argentina; Brasil.

Abstract. This paper proposes a comparative analysis of the various options of State intervention in the sugar agroindustry, which were implemented in Brazil and Argentina beginning in the 1880s. Overproduction crisis, loss of international competitiveness, conflicts among the various actors and production zones, all led to new institutional

* Una primera versión de este trabajo fue presentada en el simposio Trabajo, Población y Comercio en el Mundo Contemporáneo: Estudio Comparativo de Brasil-Argentina del Tercer Congreso Latinoamericano de Historia Económica (CLADHE III)-XXIII Jornadas de Historia Económica de la Asociación Argentina de Historia Económica, Bariloche, octubre de 2012. Técnicas.

** Instituto Superior de Estudios Sociales, Consejo Nacional de Investigaciones Científicas y

Am. Lat. Hist. Econ., año 22, núm. 3, septiembre-diciembre, 2015, pp. 44-75 
arrangements in each country, as they sought to increase prices, harmonize interests and bring planning to an always complex market. The analysis closes in 1937-1938 with the start of the Estado Novo experience in Brazil, which increases state intervention, and the failure, in Argentina, of the attempt to approve a law which would involve the State decisively in the development of the sugar industry.

Key words: State; sugar agroindustry; Argentina; Brazil.

Fecha de recepción: 28 de julio de 2014. Fecha de aceptación: 30 de septiembre de 2014 .

\section{INTRODUCCIÓN}

$\mathrm{E}$ 1 análisis que proponemos sobre el intervencionismo estatal en materia azucarera implica examinar los instrumentos de política económica aplicados en su contexto histórico específico, para lo cual será necesario interrelacionar numerosas variables. La relación cambiante entre la oferta y la demanda doméstica, las alternativas del mercado mundial del azúcar, la importancia relativa de las regiones productoras y las interpelaciones de los actores sociales involucrados en el proceso productivo se encuentran entre las más relevantes. Un aspecto de particular interés serán las dificultades que enfrentaron los sectores interesados en promover diversas formas de intervención estatal con el fin de sostener y hacer efectivas las disposiciones para valorizar la producción o promover las exportaciones, esenciales a la hora de intentar comprender la evolución de la actividad en cada uno de los países. Por tales razones, un estudio comparativo de estos avatares puede aportar al mejor conocimiento del curso que tomó hasta nuestros días la agroindustria en Argentina y Brasil.

La producción azucarera fue durante el periodo colonial, y por lo menos hasta inicios del siglo XIX, la actividad económica más relevante de Brasil, implantada de manera desigual en casi todo su territorio, aunque con un marcado epicentro en el Nordeste, donde tenía un neto perfil exportador. En el contexto nacional perdió centralidad cuando el retroceso de la presencia del azúcar brasileño en el mercado mundial coincidió con la expansión de las plantaciones de café en el interior de São Paulo y Río de Janeiro, producto que se convirtió en la exportación principal brasileña durante la segunda mitad del siglo XIX. Recién avanzando el siglo XX la caña de azúcar pudo recuperar una posición destacada dentro del sector agropecuario, aunque -sin que se renunciara a la antigua vocación exportadora- el principal incentivo del desarrollo de la cultura estuvo en la demanda de un expansivo mercado interno. La producción de azúcar y aguardiente en el actual territorio argentino también reconoce orígenes coloniales, aunque se trataba de emprendimientos a escala muy reducida 
localizados en las provincias del actual Nordeste, en Corrientes y Misiones, que no alimentaban flujos comerciales de importancia. Tras años de lenta evolución, en las dos últimas décadas del siglo XIX la producción comercial de azúcar a gran escala se expandió y modernizó radicalmente en la provincia de Tucumán, para constituirse hasta el presente en una de las actividades económicas más importantes del norte argentino. Aunque la exportación nunca estuvo ausente en el horizonte económico de los productores, la producción se orientó casi exclusivamente a satisfacer el mercado doméstico, sostenido desde la década de 1880 por un marco arancelario protector.

Las diferencias en la gestación y estructuración de los complejos azucareros de ambos países son muy marcadas. A la mayor tradición brasileña en la producción del dulce hay que agregar una diversidad regional más compleja, una diferente estructura de clases donde la impronta de la esclavitud no es un dato menor y otro tipo de conformación del Estado y el sistema político. Mientras en Argentina las áreas azucareras se localizaban casi con exclusividad en las provincias norteñas de Tucumán, Salta y Jujuy, en Brasil la cultura canavieira se implantó sólidamente en casi toda su inmensa geografía.

No obstante, el ejercicio comparativo propuesto es factible por la naturaleza de las crisis que sacudieron periódicamente la actividad en ambos países, por las intervenciones estatales que las mismas promovieron, por las tensiones inherentes a los complejos productivos cañeros y por el comportamiento de los actores (usineiros e "industriales", lavradores, fornecedores y "cañeros independientes"). Por otro lado, del cotejo de semejanzas y discordancias podremos formular preguntas cuyas respuestas pueden aportar al mejor conocimiento de la dinámica social y política de los espacios donde se implantó la cultura de la caña de azúcar; sobre la compleja ingeniería de leyes, reglamentos y disposiciones que se diseñaron para preservar, valorizar, ordenar y regular la actividad; sobre las ideas y principios con los que se justificaron las políticas que cada país implementó sobre el sector. Asimismo, se intentará echar luz sobre los esfuerzos y estrategias con las que los actores económicos y sociales involucrados pretendían, con suerte diversa, imponer sus intereses sectoriales al interés general.

Remarcamos que durante el periodo colonial la actividad azucarera no fue relevante en el territorio que se conformaría, durante la segunda mitad del siglo XIX, en la República Argentina. En la provincia de Tucumán el azúcar y el aguardiente se transformaron en productos comerciales en la tercera década del siglo XIX, cuya base era una tecnología primitiva (trapiches "de palo" con tracción animal, cocimiento de los jugos a cielo abierto, etc.), aunque en los años sesenta y setenta se incorporaron de manera lenta pero sostenida trapiches de hierro movidos hidráulicamen- 
te, evaporadores y tachos de cocimiento al vacío, centrífugas, máquinas a vapor, etc., proceso que aceleró de manera notable la conexión ferroviaria de Tucumán con el puerto fluvial de Rosario, acaecida en 1876, y por la Ley de Aduanas del mismo año, que gravó todas las importaciones con $25 \%$ ad valorem.

Sin embargo, la expansión del azúcar tucumano se enfrentó a los costos menores del azúcar importado en un contexto de baja sostenida de precios, ocasionada por la irrupción del azúcar de remolacha europea y los subsidios a la exportación con los que los países del Viejo Mundo desplazaban de los mercados a los azúcares de caña en beneficio de la producción propia. En ese contexto, el reto de los productores tucumanos, muy enraizados tanto en las redes de la política local como en la nacional, fue conquistar el mercado doméstico -en expansión por la afluencia masiva de inmigrantes- mediante una operación esencialmente política: una protección aduanera creciente, que se garantizó a través de una alianza entre las elites de las provincias no pampeanas y también sectores de la provincia de Buenos Aires, para quienes aceptar un esquema arancelario que contrariara el dominante clima de ideas librecambistas no constituía un principio irrenunciable.

Lo que las elites no pampeanas ofrecieron a cambio de esta concesión -benéfica también para la industria vinícola de las provincias de Mendoza y San Juan- fue asegurar la gobernabilidad de un país cuyos últimos episodios de la guerra civil iniciada con el proceso independentista se prolongaron hasta 1880. Ello no era poco, pues sin esa condición era impensable que el "progreso" -afluencia de centenares de miles de inmigrantes europeos, de capitales del mismo origen, expansión de la frontera agraria, trazado de miles de kilómetros de vías férreas, desarrollo de un sistema financiero, expansión de la educación pública y la modernización y centralización institucional- se abriera paso vertiginosamente (como lo hizo) y que las fértiles llanuras pampeanas se articularan íntimamente con la demanda de productos primarios (cereales, lanas, carnes) que la expansión del capitalismo europeo en su fase imperial reclamaba (véase Balán, 1978; Cortés Conde, 1979; Guy, 1981).

En efecto, la beneficiosa articulación de Tucumán y de las restantes provincias norteñas con el progreso pampeano tuvo como condición necesaria un esquema de protección arancelaria, que -iniciado con la Ley de Aduana de 1876- se fortaleció y perfeccionó con legislación específica en defensa de la producción azucarera, iniciativas aprobadas por el Congreso de la Nación en 1882, 1884 y 1888 (Sánchez Román, 2005, p. 176). Tal esquema impulsó la instalación de ingenios de moderna tecnología y la expansión del área cultivada con caña. Así, para 1895 el azúcar norteño desplazó totalmente a los productos importados del mercado doméstico. 
Una medida complementaria, la llamada "Ley de Primas", votada en 1897 para superar la caída de precios ocasionada por la acumulación de stocks derivada de la extraordinaria zafra de 1896, promovió la exportación a pérdida de excedentes, lo que se compensaba con un impuesto al consumo interno, es decir con un sobreprecio sufragado por los consumidores.

El modelo proteccionista, fundado discursivamente en la necesidad de defender la industria y el trabajo nacional y amparar la vida y el sustento económico de una vasta región interior -conformadas no sólo por las provincias productoras, sino por aquellas proveedoras de insumos $y$, fundamentalmente, la mano de obra de ingenios y plantíos de caña-, subsistió hasta nuestros días, resistiendo incluso la ofensiva neoliberal de la década de 1990. Sin embargo, hasta ese punto llegó la influencia política de los productores azucareros y de las provincias norteñas, que no pudieron evitar que los intereses y fuerzas políticas apegados al librecambio le pusieran un férreo límite a comienzos del siglo xx: los "derechos del consumidor", lo que quedó establecido en la Ley Saavedra Lamas de 1912. Posteriormente, en los años veinte, el principio de la justicia distributiva promovió modificaciones de peso en la política azucarera, en especial en lo relativo a las competencias del Estado tucumano, estableciendo pautas que se aplicarían bajo la tutela y el arbitraje estatal para la determinación de un "precio justo" de la materia prima producida por los "cañeros independientes" tucumanos, lo que dio lugar al nacimiento de la primera experiencia reguladora de la producción de largo alcance.

El laudo presidencial Alvear, solicitado por las partes en conflicto -industriales y "cañeros"-, planteó la fórmula que determinaba el precio de la materia prima sobre la base de la riqueza sacarina, estableciéndose en paralelo la Cámara Gremial de Productores de Azúcar, de carácter permanente, con representantes de industriales y cañeros, cuya función primordial consistía en resolver los disensos en torno a los contratos de compraventa de materia prima sobre la base de la equidad y la razonabilidad.

Estos elementos conformaron el marco institucional en que se desarrolló la actividad azucarera desde su radical reconversión productiva en la década de 1880 hasta mediados de la de 1940, periodo en el que se superaron los impactos de la crisis de sobreproducción en 1896-1898 y la que tuvo lugar a mediados de la década de 1920, con el consecuente derrumbe de precios, quiebras, cierres de ingenios, forzadas recomposiciones societarias, etc., así como una crisis biológica, la "plaga del mosaico", que diezmó los cañaverales tucumanos en la segunda década del siglo XX. En ese contexto la protección aduanera permitió que las inestabilidades propias de un mercado tan sensible como el azucarero no arruinaran el experimento de levantar un complejo agroindustrial en el límite agroecológico que hace posible la cultura y que, en un marco fluctuante y de gran 
variabilidad, aumentó su capacidad productiva al mejorar la eficiencia tecnológica y sus rendimientos agrícolas e industriales.

El desarrollo de la agroindustria azucarera en Brasil presenta un panorama más complejo que el caso argentino, complejidad derivada de una mayor diversidad regional y de las dificultades para consolidar una centralización política y económica, consumada en el Plata en la década de 1880. Mientras en Argentina la transformación de los viejos ingenios en modernas fábricas fue un fenómeno vertiginoso, que puede considerarse concluido a mediados de la década de 1880, en Brasil la transición del viejo bangüê a la moderna usina, pasando por la experiencia del ingenio central, aconteció lentamente y de forma desigual. De tal modo, la coexistencia de unidades de producción de escala y naturaleza muy diferentes se prolongó en casi todas las regiones productoras hasta avanzado el siglo XX. Consecuentemente, la rapadura y los azúcares de baja calidad estuvieron enraizados en el consumo popular de las regiones interiores, compitiendo con la producción de los ingenios centrales y de las usinas.

En Brasil, la década de 1880 fue un periodo de cambios institucionales trascendentes, como la crisis final del sistema esclavista y la sustitución del imperio por la república. En los planos económico y social ya era un hecho la decadencia definitiva de la vieja aristocracia del azúcar (la de los senhores de engenho), reemplazada en la constelación de las clases dominantes por los fazendeiros do café, lo que implicaba el traslado del centro económico del país del Nordeste al sureste (principalmente al estado de São Paulo). Esta pérdida de importancia política y social de los senhores de engenho se acentuó cuando se hizo crítica la caída de la participación del azúcar en la estructura de las las exportaciones brasileñas: representando $10 \%$ de las exportaciones entre 1881 y 1890 , cayeron a $5.7 \%$ y a $1.2 \%$, respectivamente, en las décadas de 1891-1900 y 1901-1910 (Szmrecsányi, 1979, p. 164).

El proceso era consecuencia de la pérdida de competitividad de los azúcares brasileños frente a sus similares europeos de remolacha y de países productores de azúcar de caña, como Cuba y Java, que sumaban a menores costos de producción y economías de escala las ventajas de contar con acceso a mercados preferenciales. De ese modo, a comienzos del siglo $\mathrm{XX}$, en el marco de una profunda crisis de mercado y caída a pique de los beneficios empresarios, el destino del azúcar brasileño se limitó casi con exclusividad a abastecer el mercado doméstico. Referente a esa coyuntura, a fines de la década de 1930 una publicación oficial afirmaba que "Os preços baixaram vertiginosamente e prosseguiram anos a fio na pendente, arrastando consigo empresas, trabalho, capital, crédito, tudo" (Brasil, 1939, p. 43). Ello implicaba para la principal región productora, el Nordeste, un interés adicional a la preocupación por recuperar la competitividad perdida en el mercado internacional: preservar para sus azúcares 
los principales centros consumidores del Centro-Sul, Río de Janeiro y el ascendente estado de São Paulo, donde se combinaban la afluencia de inmigrantes por el auge cafetero, un proceso de industrialización creciente y el aumento de la renta regional.

En contra de esas expectativas, la cercanía con relación a los mercados de mayor nivel de consumo incentivó en Campos (Río de Janeiro) y en el oeste paulista la creación de nuevas usinas (y ampliación de las existentes) con la consecuente conquista progresiva por parte de los mismos de cuotas crecientes del mercado nacional.

En relación con las intervenciones gubernamentales sobre el mercado azucarero, en el marco de un clima de ideas dominado por la doctrina del laissez-faire, se desplegó un conjunto de prácticas que tuvieron por objeto valorizar y proteger la producción de la agroindustria en coyunturas muy variadas. Dejando a un lado las modalidades de intervención del periodo colonial, la tarifa Alves Branca de 1844, que inauguró el proteccionismo en general $-\mathrm{y}$, consecuentemente, también el azucarero en el Brasil independiente-, y las garantías para el establecimiento de engenhos centrais (Barros Meira, 2007, 2014) otorgadas en las décadas de 1870 y 1880 quizá sean los grandes ejemplos de esta intervención estatal en auxilio de la producción azucarera durante el imperio. Con referencia a los engenhos centrais, Gabriel Bittencourt (1999) afirma que entre todos los emprendimientos privados como "Portos e diques, melhoramentos urbanos, assim como escassas e exígua rodovias e canais [...] unidades fabris [...] Nada, porém, no setor industrial pode se comparado aos engenhos ou usinas centrais de açúcar subsidiados pelo Estado, quando a transformação de regime do trabalho perturba a prosperidade da lavoura" (p. 34).

La intensidad y los efectos de estas intervenciones son materia de controversia en la historiografía brasileña. Autores como Tamás Szmrecsányi (1979) y Alcides Ribeiro Soares (2000), que toman como referencia las políticas ejecutadas por el Estado central brasileño a partir de 1931, llaman la atención sobre el predominio de las políticas liberales durante la etapa republicana: Szmrecsányi (1979) apunta que "Na verdade, o intervencionismo estatal na economia açucareira só não predominou durante o Imperio e nas primeiras décadas do regime republicano" (p. 162); y Ribeiro Soares (2000) señala que "O período compreendido entre o término da experiência dos engenhos centrais e a limitação da produção (1890-1933) é caracterizado por relativo abandono da economia açucareira nacional pelo Governo Republicano. Esta atividade passou a desenvolver-se basicamente em função do mercado interno e sob um clima de predominante liberalismo" (p. 8).

Sin embargo, esta indubitable distinción fue relativizada por el historiador argentino Roberto Pucci (1998), quien propuso que la naturaleza de 
las políticas durante el imperio y la primera república eran (sin matices) francamente intervencionistas:

la asunción [...] generalizada en los estudios sobre aquel periodo de que las clases dirigentes profesaron y practicaron el liberalismo económico [...] y la intervención azucarera masiva desplegada por el régimen surgido en 1930 [...] contribuyeron a eclipsar en las descripciones históricas posteriores el activo rol desempeñado por el Estado imperial y republicano en toda la vida económica nacional, incluyendo el sector azucarero [...] para lo cual recurrió a un amplio arsenal de medidas: inversiones garantidas, exenciones impositivas, subsidios directos, inversiones estatales en compañías privadas, subsidios o primas indirectas a la exportación, concesión de bajas tarifas de transporte ferroviario y marítimo, construcción de silos y almacenajes, etc. (p. 11). ${ }^{1}$

Salvo los ejemplos dados (la protección arancelaria y las garantías para la instalación de los ingenios centrales) y más allá de la variada gama de recursos pensados y aplicados para valorizar la producción y recuperar los espacios perdidos en el mercado internacional azucarero, las otras medidas fueron de dudosa eficacia y/o de aplicación incierta, además de controversiales. Lo demostraría el fracaso en la primera década del siglo XX de las propuestas para la adopción de primas a la exportación -que imitarían la enraizada práctica con la que Europa hizo retroceder en el mercado mundial al azúcar de caña en beneficio del azúcar de remolacha-, pese a la existencia de antecedentes de intervención de este tipo para la valorización de los precios del café. Efectivamente, destacados representantes de los usineiros del sureste insistieron por más de una década en la necesidad de aplicar este tipo de medida, pues la entendían como la única alternativa para generar las condiciones de incentivo para la exportación y así aliviar el mercado interno de los excesos de azúcares del Nordeste (Barros Meira, 2013). Pero los usineiros nordestinos resistieron este camino en el entendimiento de que un retorno al esquema de libre comercio, promovido por Inglaterra, y la adhesión brasileña a los acuerdos de Bruselas (que establecían "derechos diferenciales" a los azúcares exportados con subsidios), era la dirección adecuada para recuperar las posiciones perdidas en los mercados extranjeros. Sin embargo, la adhesión de Brasil al Acuerdo de Bruselas en 1906 no deparó ninguno de los resultados esperados, pues no lograron exportarse los excedentes, no disminuyeron los stocks ni se tonificaron los precios en el mercado interno. Por lo demás, Brasil fue igualmente san-

\footnotetext{
${ }^{1}$ Una versión resumida de este trabajo fue publicada bajo el título de "Crecimiento, mercados y políticas del azúcar, 1880-1930: los casos de Brasil y de la Argentina” (noviembre, 1999). Realidad Económica, 167.
} 
cionado por la Comisión Permanente a fines de 1908 -junto a Argentina, Brasil, Chile, Costa Rica, México y Nicaragua- por favorecer con algún tipo de subsidio a sus azúcares (Moura Filho, 2012-2013, p. 236).

Otro ejemplo de la inconsistencia del intervencionismo brasileño en el mercado azucarero fue la Caja Nacional de Exportación de Azúcar, creada en 1922 bajo la dirección compartida de los ministerios de Hacienda y de Agricultura con el propósito de sostener los precios en el mercado doméstico exportando los excedentes, la que no llegó a tomar ninguna acción efectiva pese al contexto de aguda sobreproducción y las presiones y reivindicaciones de usineiros y lavradores:

A instituição contaria com recursos das exportações do açúcar e do imposto de consumo de 30 réis por quilo de açúcar de qualquer tipo, cuja cobrança seria feita a partir da data do decreto -7 de janeiro de 1922. A Caixa também teria a função de promover a propaganda do açúcar brasileiro no exterior e "estimular a exportação de doces, confeitos, chocolates, etc., de produção nacional". Além do ato de sua criação, a pesquisa bibliográfica não encontrou menção a qualquer atuação da Caixa de Exportação. Ao que tudo indica, a instituição sequer chegou a operar (Brollo, 2009, p. 223).

Con independencia de cuál haya sido la efectividad e importancia de estas medidas para salvar a la agroindustria canavieira en las críticas circunstancias por las que atravesó a fines del siglo XIX y comienzos del XX, algunos elementos aparecen evidentes. En primer lugar, el pragmatismo que guiaba las políticas estatales en un contexto de fuerte presencia del liberalismo económico en los debates públicos a la hora de actuar frente a las crisis de mercados y caídas de precios, como también para asegurar con recursos estatales (esto vale para el sistema de garantías aplicado para promover la instalación de engenhos centrais) inversiones privadas en sectores productivos y de servicios. En este sentido, y como ya se ha afirmado, las crisis de sobreproducción del café a inicios del periodo republicano, que tuvieron como respuestas gubernamentales medidas para contener la oferta y sustentar los precios, sentaron precedentes para la intervención estatal en el conjunto de las actividades económicas agrícolas.

En segundo lugar, las preocupaciones gubernamentales no se reducían a garantizar beneficios al sector empresarial y a proteger la actividad de las crisis de sobreproducción y la debacle de los precios. El Estado brasileño también intervino al limitar las exportaciones para garantizar el consumo interno amenazado por la falta de stocks en coyunturas favorables a la exportación, tal como sucedió durante la Gran Guerra de 1914-1918 (Brasil, 1939, pp. 45-46). Como en el caso argentino, el concepto de defensa del consumidor frente a la posibilidad de precios exorbitantes de productos de 
primera necesidad no quedaba fuera de la consideración de los gobiernos a la hora de definir las políticas públicas.

En tercer lugar, las medidas con las que se intentó enfrentar los diversos momentos críticos por los que atravesó la producción azucarera durante la primera república fueron diseñadas sólo para cada coyuntura. No integraban un plan coherente para atender siquiera en el mediano plazo los problemas de la producción, comercialización y consumo del dulce.

Por otro lado, muchas de estas medidas eran respuestas acotadas a los marcos estatales, sin posibilidades de proyectarse a escala nacional. En este punto es pertinente remitir a Szmrecsányi (1979), para quien "a única medida concreta do Governo Federal durante da década de 1910 foi a regulamentação, através do Decreto 10.076, de 19/02/1913, das estações experimentais para cana-de-açúcar, é a inauguração, no mesmo ano, da Estação Experimental de Campos, a qual, no entanto, só veio realmente a iniciar os seus trabalhos em 1916" (p. 166).

Naturalmente, el Estado que promovió con mayor intensidad e insistencia intervenciones en los mercados azucareros fue Pernambuco. No sólo por su casi absoluta dependencia de las exportaciones azucareras, sino también por las conflictivas relaciones entre propietarios de ingenios y usinas y labradores, cuyas relaciones jurídicas requerían ser reguladas. Quizá la más relevante haya sido la Ley 1.850 del 31 de diciembre de 1926, que autorizaba al gobierno estatal a cooperar con el Instituto do Defesa do Açúcar, sociedad cooperativa constituida ese mismo año por usineiros y lavradores con la finalidad de intervenir en el mercado con diversos instrumentos, entre otros: retirar del mercado volúmenes necesarios de azúcar para sostener los precios, determinación de la época de ventas, incentivar el uso de alcohol combustible (Azevedo, 1948, pp. 204-205). Al respecto, no está de más remitirnos a Szmrecsányi y Veiga Filho (1999), para quienes también el estado de São Paulo dio importantes pasos en la misma década y en la misma dirección que Pernambuco:

tudo indica que as políticas de defesa e de fomento da agroindústria canavieira já estavam no ar antes da mudança do regime político e da criação do IAA. E isto não estava ocorrendo apenas no Nordeste, onde tendências neste sentido seriam de se esperar, devido á amplitude e ao enraizamento dos interesses vinculados a agroindústria canavieira, mas também em São Paulo, cujo sub-setor açucareiro estava dando os primeiros passos na sua arrancada definitiva. É claro que não se tratava de uma tentativa de estatizar a produção açucareira, mas antes de colocar o Estado a serviço de certos grupos empresariais. (p. 81).

Aunque muchas de estas iniciativas puedan considerarse antecedentes necesarios del complejo sistema de fomento y regulación de la activi- 
dad a escala nacional desplegada en la década de 1930, en comparación con las políticas promovidas por la Comissão de Defesa da Produção do Açúcar (1931) y por el Instituto do Açúcar e do Álcool (1933), más bien funcionaron como correctivos de un esquema de laissez-faire que la república no se planteaba alterar ni reemplazar, que además era compatible con la preservación del mercado doméstico para la producción nacional a través de la aplicación de tarifas proteccionistas, tal como Moura Filho (2012-2013) lo apunta: "Tendo reduzido a tarifa sobre açúcar estrangeiro a 200 réis em fevereiro de 1906, dois anos depois, o Brasil resolveu elevar o imposto de importação para 400 réis por $\mathrm{kg}$, possivelmente demonstrando que, uma vez penalizado, não havia porque não buscar maior arrecadação tributária" (p. 11).

Esta conjunción y compatibilidad entre un ideario económico liberal y prácticas intervencionistas, de la que resultaban sólo respuestas específicas a cada coyuntura, se tornó inviable gracias a la profundidad de la crisis económica internacional de los años treinta, cuyos efectos -que atacaban de raíz los fundamentos de un modelo sustentado en las actividades agropecuarias orientadas a la exportación- promovieron una mudanza radical de las políticas públicas.

El impacto de estas circunstancias particulares impulsó la "ruptura social y cultural" (Szmrecsányi y Ramos, 2005) que implicó la revolución de 1930, y que en el plano de la economía se manifestó en el diseño de una estrategia asumida como política de Estado, cuyo objetivo era el desarrollo de las fuerzas productivas nacionales, primordialmente fundado en el consumo interno. Esas condiciones generales explican el proyecto sucroalcoholero de largo aliento aplicado en toda la geografía nacional que se inició con la Comissão de Defesa da Produção do Açúcar y el Instituto do Açúcar e do Álcool y que profundizó el Estatuto de Lavoura Canavieira, aprobado en 1941.

\section{Cuestiones, PROCESOS}

Una característica común que enmarcó la evolución de los complejos azucareros de ambos países puede iluminar el proceso, particularmente en lo que se refiere a las fuerzas profundas que animaban los a veces larvados, a veces crispados, conflictos interregionales. Nos referimos al conflicto o a las tensiones norte-sur, en las que un conjunto de factores -en los dos casos- favorecían de manera clara al sur. Ya a fines de siglo XIX, tanto el Norte argentino como el Nordeste brasileño (que durante el periodo colonial compartieron posiciones de mayor relevancia económica y demográfica con relación al área pampeana y a la región centro-sur brasileña, 
respectivamente) disminuyeron de manera notable su peso específico e influencia económica relativa en el contexto nacional, lo que contrastaba con el extraordinario crecimiento de Buenos Aires y São Paulo y sus áreas de influencia. El desequilibrio demográfico ocasionado por la llegada masiva de inmigrantes europeos y de migrantes internos, atraídos por las perspectivas de empleos e ingresos que ofrecían estas nuevas áreas centrales por su posibilidad de insertarse en el mercado mundial sobre la base de productos para los que contaban con evidentes ventajas comparativas (cereales, carnes, café), no tardó en expresarse a través del debilitamiento político de las elites azucareras norteña (Argentina) y nordestina (Brasil), aunque hayan conservado intacta su voluntad de defender sus intereses y preservar las parcelas de poder y el prestigio social que habían conquistado en épocas más gloriosas.

Los principios e instrumentos económicos relacionados con el azúcar, bajo los que ambos países transitaron desde fines del siglo XIX hasta la crisis de la década de 1930, no fueron exactamente los mismos, aunque fueron determinados por una circunstancia similar: la orientación de la producción se dirigió inevitablemente a satisfacer las necesidades del consumo interno. En el caso argentino, alentado por el esquema proteccionista inaugurado por la Ley de Aduana de 1876, el parque industrial se reconvirtió de manera radical en menos de una década, desapareciendo los tradicionales ingenios de vieja tecnología, que fueron remplazados por fábricas de última generación; aunque la inserción en el mercado mundial no fue la perspectiva más importante para los industriales locales, salvo como una alternativa para volcar los excedentes en tiempos de sobreproducción y como recurso para tonificar los precios internos. Por su parte, la más antigua economía azucarera brasileña -debilitada su presencia en el mercado internacional por la pérdida de competitividad frente a la producción europea y las más pujantes economías cañeras de Cuba y Javaoptó también por refugiarse cada vez más en el mercado doméstico.

En Brasil, los nuevos tiempos alentaron el surgimiento de un nuevo modelo fundado en la preeminencia de las usinas luego del fracaso del experimento de los engenhos centrais, las que poseían un alto grado de integración vertical y que, por lo tanto, tendían a consolidar el latifundio. Iniciado en el Nordeste, el modelo se desarrolló también en la región paulista, "ligadas principalmente aos lucros advindos dessas novas e ricas regiões cafeeiras" (Barros Meira, 2008, p. 10), en donde las usinas se beneficiaban con las facilidades de acceso y los menores costos para proveer al mayor, más dinámico y próspero segmento del mercado nacional de consumo, el propio estado de São Paulo. Así, las antiguas zonas productoras nordestinas (Pernambuco, Alagoas y Sergipe), en las que las usinas coexistían con viejos engenhos y banguês y donde persistía una estructura agraria más 
compleja, se vieron amenazadas por la tendencia al autoabastecimiento de São Paulo. A su vez, en Campos (Río de Janeiro) "se revelou menos forte o poder de atração das usinas, prevaleceu a distinção entre a parte industrial e a parte agrícola, acentuando-se o parcelamento da propriedade como um processo de democratização" (Azevedo, 1948, p. 230).

Mientras tanto, en Argentina se definieron también modelos diferentes, aunque fueran sólo dos. ${ }^{2}$ En Tucumán se combinaba la presencia de ingenios con un alto nivel de integración vertical con otros en los que la dependencia hacia un amplio espectro de productores cañeros (grandes y medianos propietarios de la tierra, arrendatarios, minifundistas, "colonos") $)^{3}$ era muy importante, por lo que entre los actores involucrados se destacaron desde un comienzo los llamados "cañeros independientes". En las provincias de Salta y Jujuy prevalecieron grandes ingenios integrados verticalmente. Aquí los "cañeros independientes" siempre fueron un reducido grupo de grandes propietarios, asociados de manera íntima con las empresas agroindustriales, por lo que la presencia de un activo campesinado azucarero (como el tucumano) fue inexistente. Naturalmente, en función de sus respectivas estructuras económicas y paisajes sociales, los problemas específicos de cada uno de estos modelos fueron diferentes, como diferentes fueron las soluciones que se procuraron desde los poderes públicos al momento de definir intervenciones.

Hemos afirmado que la protección aduanera fue la principal herramienta que alentó el desarrollo azucarero argentino desde la década de 1880. La medida fue acompañada también con exenciones impositivas para la importación de maquinaria en la primera etapa de modernización, así como fletes preferenciales de los ferrocarriles del Estado, también en la misma época. Además de estas medidas, el Estado-nación argentino sólo complementó la política de fomento a la actividad azucarera con la mencionada Ley de Primas de 1897, la que sin embargo no pudo continuar siendo aplicada por las cláusulas de los acuerdos de Bruselas de 1902, que penalizaban los azúcares volcados al mercado mundial con el auxilio de subsidios (véase Moura Filho, 2012-2013). Quizá la explicación de ello se encuentre en la pérdida paulatina de poder político de la elite norteña, cuyo papel decisivo para garantizar la gobernabilidad del país, en las décadas de 1880 y 1890, se diluyó con la disminución del peso demográfico

\footnotetext{
${ }^{2}$ Aunque además de en las provincias de Tucumán, Salta y Jujuy, la caña de azúcar se cultivó comercialmente en Chaco, Formosa, norte de Santa Fe, Corrientes y Misiones (lo que en la jerga azucarera se denominó "el Litoral"), la participación de los ingenios localizados en tales provincias y territorios nacionales ha sido siempre ínfima en el contexto nacional, por lo que pueden desestimarse en función de los objetivos de nuestro análisis.

${ }^{3}$ En Tucumán se denominaba "colonos" a los encargados de las "colonias" de los ingenios, recortes de latifundios para su mejor explotación o administración.
} 
relativo de la región y con un nuevo acuerdo institucional pactado entre las elites tradicionales y los emergentes sectores subalternos (clases medias, trabajadores de origen inmigratorio de Buenos Aires y las provincias del litoral), sellado con la reforma electoral de 1912 que instituyó el voto universal masculino y obligatorio. De ese modo perdió vigor la capacidad de presentar el desarrollo azucarero como un asunto de interés general, por lo que quedó reducida su importancia al de una "economía regional".

Quizá ello explique que el Estado central argentino haya optado por respetar los principios de la libre concurrencia antes que complementar la protección azucarera con mecanismos regulatorios (limitaciones a producción, cuotas, etc.), como sí se vio obligada a hacer Tucumán, como se verá. $\mathrm{Ni}$ siquiera en los años de 1930, cuando bajo el impacto de la recesión mundial se adoptaron numerosas medidas intervencionistas y se crearon instituciones que tenían como objeto regular determinadas actividades (la Junta Reguladora de Granos y similares de la carne, del vino y de la yerba mate), se avanzó en la misma dirección en cuanto al azúcar. Es más, una proyectada Ley Azucarera, muy debatida a fines de la década, no pudo ser aprobada en el Congreso Nacional.

En cuanto a Brasil, que hasta el momento había experimentado con varias medidas intervencionistas (algunas de las cuales fueron de dudosa efectividad) que no dejaron de ser respuestas puntuales a determinadas coyunturas, desplegó en la década de 1930 un ambicioso programa de "defensa” de la actividad azucarera, en el que se destacó la creación en 1933 del Instituto do Açucar e do Alcool -órgano estatal autárquico en el que participaban los usineiros y, desde 1934, los banguêseiros, los plantadores y los fornecedores-, que contaba con importantes prerrogativas regulatorias, aunque las presiones de los usineiros modificaron sustancialmente el proyecto oficial bloqueando la aspiración gubernamental de intervenir en todos los aspectos de la agroindustria, en particular en lo referido a la posibilidad de establecer límites a la producción de azúcar (véase Guimarães, 2013).

No deja de llamar la atención el contraste entre las respuestas argentina y brasileña frente a la coyuntura más crítica que hasta entonces atravesaba el sistema capitalista, con un inédito descalabro de los mercados y el dramático descenso de flujos comerciales y precios. Contraste que no se limita a la renuncia a establecer pautas regulatorias por parte del Estado nacional argentino en comparación con la profundidad de las disposiciones brasileñas, sino también a la decisión de este país de implementar una política de fomento al alcohol anhidro (aditivo obligatorio a la gasolina importada desde 1931), con lo cual, además de proteger indirectamente la producción azucarera, se intervenía en el mercado de combustibles con una estrategia que procuraba el ahorro de divisas a través de la sustitución de importaciones: 
Mesmo com todas essas medidas de incentivo à produção e ao consumo do álcoolmotor, esse produto, no período 1932-1937, não se constituiu num forte mecanismo de defesa da produçâo açucareira [...] O principal obstáculo era a recusa dos produtores de açúcar em converter os seus excessos de açúcar em álcool [...] $\mathrm{O}$ álcool anidro produzido [...] foi inferior ao necessário para a quota legal estabelecida pelo decreto $\mathrm{N}^{\mathrm{o}}$ 19.717/1931, que tornava obrigatória a aquisição de álcool na proporção de 5\% da gasolina importada (Guimarães, 2013, p. 16).

Buscando dar respuesta a las razones de esta discordancia, quizá podría pensarse que la misma tendría que ver con la implantación desigual de la cultura cañera en cada caso y con la mayor injerencia del sector más concentrado de las clases dominantes brasileñas en el negocio azucarero. Y especular que si la agroindustria argentina logró eludir grandes catástrofes sin una intervención más radical del Estado nacional en una coyuntura de aguda crisis, tal intervención habría sido innecesaria. Sin embargo, la provincia de Tucumán (que aplicaba un esquema regulatorio desde 1928) asumió esa función, nada desdeñable toda vez que esa provincia concentraba la mayor parte de la producción azucarera nacional. En ese sentido, lo que realmente ocurrió es que a fines de la década de 1920 y comienzos de la de 1930, en Argentina un estado provincial atendió la problemática que en Brasil asumió el Estado federal, con el resultado (para nada paradójico) de que esa circunstancia benefició a los ingenios localizados en Salta y Jujuy, que además de obtener jugosas ganancias con los precios tonificados por la limitación productiva tucumana no eran sometidos a pauta regulatoria alguna. Así, avanzaron decisivamente en su participación relativa en la producción azucarera en desmedro, precisamente, de los ingenios tucumanos.

\section{ESTRUCTURAS, CRISIS Y ACTORES}

Las características de la producción de azúcar y las del funcionamiento del mercado azucarero fijaban ciertas condiciones estructurales de carácter general en esta cultura, las que explican determinadas tendencias y políticas de intervención estatal en casi todos los países productores en el periodo que nos ocupa, entre los que estaban incluidos Argentina y Brasil. Por un lado, la base agrícola de la actividad suponía una sensible dependencia de factores climáticos y biológicos no controlables, lo que implicaba frecuentes desajustes entre oferta y demanda, y que con recurrencia la capacidad instalada del parque fabril resultaba sobredimensionada con relación al consumo. Por otra parte, la inelasticidad de la demanda, inherente a un producto que en gran medida se destinaba al consumo directo, inducía 
pronunciados movimientos de los precios, pudiéndolos bajar a niveles de quebranto en coyunturas de sobreoferta, o subirlos abruptamente cuando se agotaban los stocks, lo que generaba virtuales desabastecimientos. A su vez, el cuadro se tornaba más complejo con las prácticas generalizadas de dumping y con la exportación subsidiada de excedentes europeos de azúcar de remolacha en el mercado internacional, lo que agregó motivos suficientes para promover barreras aduaneras proteccionistas, restricciones a la exportación, incentivos para la exportación de excedentes y diversas medidas de tipo regulatorio para resguardar la rentabilidad empresaria, la estabilidad de los precios y garantizar un normal abastecimiento de los centros de consumo.

En las situaciones de crisis a las que se hizo referencia se agudizaron los choques de intereses entre los diversos actores intervinientes en el negocio azucarero, productores de materia prima (lavradores, fornecedores y "cañeros independientes"), propietarios de ingenios y usinas, comerciantes mayoristas, importadores, etc., entre los cuales el reparto de beneficios (en épocas de prosperidad) y de costos (en tiempos difíciles) no conformaban por igual a todas las partes. ${ }^{4}$

Por tales razones, las interpelaciones al Estado en pos de su intervención para ordenar el mercado, moderar las consecuencias de las crisis, garantir un "precio justo" (tanto para el producto final como para la materia prima) y regular las conflictivas relaciones sociales dentro de los complejos azucareros, fueron formuladas recurrentemente por los propios actores, en particular aquellos que constituían los eslabones más débiles de las cadenas de producción y comercialización.

En Brasil fueron los productores de Pernambuco quienes asumieron las iniciativas más relevantes para moderar los conflictos y ordenar el mercado con el auxilio estatal. En 1879 un congreso agrícola se reunía con los auspicios de la Sociedade Auxiliadora da Agricultura para solicitar al gobierno "uma lei que definisse as relações jurídicas entre proprietários e lavradores ou plantadores de cana e se recomendava a divisão do trabalho entre fábrica e o campo" (Azevedo, 1948, p. 204). En 1905, a su vez, productores de ese estado, más los de Alagoas, Sergipe, Paraíba, Rio Grande do Norte, Bahía y de la región del municipio de Campos, se reunieron en un congresso açucareiro donde resolvieron acciones para enfrentar los peligros de la superproducción y propiciar una serie de medidas que incluían la expor-

\footnotetext{
${ }^{4}$ Aunque los trabajadores, sometidos a la esclavitud en Brasil y a otras formas de coacción laboral en Argentina (sistema del "conchabo obligatorio", persecución de la "vagancia", etc.) en el siglo XIX, no fueron actores inermes y desarrollaron efectivas estrategias de resistencia individual y colectiva, incluyendo exitosos movimientos huelguísticos (como los de Tucumán de 1904 y 1923), sus demandas se incorporaron a la agenda estatal recién en los últimos años del periodo bajo estudio. Para el caso argentino, véanse Campi y Lagos (1995), y Bravo (2000).
} 
tación obligatoria de determinadas cantidades de azúcar por estado, para lo cual se crearían "sindicatos de venta de azúcar y alcohol" en las capitales estatales "para melhor defensa dos interesses comerciais dos produtores, uniformização dos preços e seguro escoamento dos produtos" (Brasil, 1939, p. 43). Bajo el auspicio del gobierno estatal, se constituyó el Instituto de Defesa do Açúcar en 1926, y en 1928 se reunieron, convocados por el gobernador del mismo estado, gobiernos y productores de varias regiones, quienes firmaron el Convênio de Recife, cuyos objetivos eran similares a los del mencionado instituto (Azevedo, 1948, p. 205). Como también se ha afirmado, el conjunto de medidas e instrumentos de intervención y regulación de la actividad propuestas por los productores y gobiernos estatales se proyectaron a escala nacional a partir de 1931 e inspiraron la creación del Instituto do Açúcar do Alcool (véase Lima, 1941).

En Argentina fueron los productores de la provincia de Tucumán los más activos promotores de iniciativas de intervención estatal, tanto en el mercado para evitar caídas incontrolables de los precios, como aquellas tendentes a regular las relaciones entre industriales y "cañeros independientes". A fines del siglo XIX y primera década del XX, la fuerte presencia de los industriales azucareros en el bloque de poder, como también la mayor cohesión del Estado central a partir de 1880, quizá hicieron innecesarias iniciativas como las del Estado de Pernambuco. De todos modos, la confluencia en 1894 de los industriales azucareros de todo el país (junto con importantes referentes de las finanzas y de la política nacional) en el Centro Azucarero Argentino (Lenis, 2009), que se constituyó en un ámbito de discusión de los problemas del sector y que funcionó como un lobby permanente ante los podres públicos, garantizaba la revisión y actualización, año tras año, de las estrategias del sector empresario en todo lo referente a política azucarera.

Sin embargo, la influencia política de los azucareros y de los políticos del norte no fue suficiente -consolidado el esquema proteccionista con las exportaciones subsidiadas a partir de 1897- para complementar la ecuación con un modelo regulacionista que redujera el área cañera bajo cultivo y estableciera cupos de producción a los ingenios. Una iniciativa de este tipo, impulsada bajo la presión del ciclo de sobreproducción del que no se lograba salir hacia 1901, tuvo que circunscribirse a la provincia de Tucumán, cuya Legislatura aprobó en 1902 y 1903 sendas leyes (conocidas como "leyes machete" o "leyes guadaña"), aunque su vigencia se limitó a esos dos años al ser declaradas inconstitucionales por la Corte Suprema de Justicia de la Nación a petición de un grupo disidente de industriales azucareros (Bravo, 1991). Hubo que esperar un cuarto de siglo, luego de atravesar un corto ciclo de subproducción y la grave crisis del "mosaico" que arrasó los cañaverales tucumanos en 1915 y 1916, para que un ensayo 
de regulación productiva se adoptara (aunque esta vez también sólo limitada al ámbito tucumano) con el consenso de todos los factores productivos, que habían solicitado al Estado que asumiera el papel de "árbitro" frente al conflicto y el clima de aguda tensión social que conmovía a Tucumán a mediados de la década de 1920 como resultado de otra coyuntura de sobreproducción, generalizada ahora a escala mundial.

Pero esta vez las demandas de los actores no se limitaron a solicitar la intervención del Estado para garantizar la rentabilidad empresaria y defender la producción nacional frente al peligro de los azúcares importados. Los "cañeros independientes", que habían consolidado su identidad social y habían logrado organizarse corporativamente (luego de varias intentonas efímeras) en 1918 en un "Centro Cañero", plantearon una nueva demanda, la de la distribución más equitativa de la renta global del sector, que se concentraba en los industriales y en los grandes comercializadores de azúcar. Si las demandas de los propietarios de ingenio (protección, subsidios a las exportaciones, control de la oferta, etc.), eran de algún modo la reivindicación de un "precio justo" del producto en un mercado muy inestable, los cañeros tucumanos, a su vez, reivindicaban un "precio justo" para la materia prima. La "huelga cañera" de 1927, que puso al campesinado tucumano del azúcar en pie de guerra durante varias semanas, fue lo que en realidad abrió el camino a un novedoso arreglo (diseñado por el presidente de la república a instancias de las partes en conflicto): el laudo Alvear, que establecía una fórmula para la fijación del precio de la caña sobre la base de considerar que los costos de producción del azúcar se repartían en partes iguales entre las labores agrícolas y la producción fabril, al tiempo que anunciaba la creación de una Comisión Nacional de Azúcar, institución que debía orientar el funcionamiento de la actividad sobre bases "científicas y racionales" (Bravo, 2009). ${ }^{5}$

$\mathrm{El}$ acuerdo, que significaba reconocer que el "precio justo" de la caña no podía resultar del libre juego de oferta y la demanda, es decir de la negociación a todas luces desigual entre cañeros e ingenios, incorporaba un nuevo concepto, una nueva "idea-fuerza" que desempeñaría a futuro una importancia decisiva en la determinación de las herramientas de la política azucarera argentina, pese a que todavía su aplicación se limitara a la geografía tucumana. En efecto, a los principios de "protección de la producción y del trabajo nacional" y de "defensa del consumidor", a partir de los cuales se había adoptado a fines del siglo XIX y comienzos del xx lo que se llamó "proteccionismo racional", se sumó el de la "justi-

${ }^{5}$ La constitución de la Comisión Nacional de Azúcar se dilató por dos años y cuando comenzó sus trabajos, en enero de 1931, lo hizo sólo con funciones asesoras de un organismo destinado al estudio de la problemática de la agroindustria. 
cia distributiva", que paulatinamente contemplaría no sólo a los cañeros (particularmente a los sectores más empobrecidos del sector, los minifundistas o "cañeros-proletarios"), sino también a los asalariados (véase Kindgard y Campi, 2006).

En el camino al decidido intervencionismo estatal, que en lo relativo a la economía azucarera asumió Brasil en la década de 1930, también tuvieron una importancia decisiva los problemas y la conflictividad social del complejo azucarero: "A marcha da economia livre para a economia dirigida não se acelerou apenas nem sobretudo pelas tendências intervencionistas do Estado autoritário, mas pela própria força das cousas e sob a pressão desses conflitos de interesses que afastavam cada vez mais, colocando-as em campos opostos, as duas classes de produtores" (Azevedo, 1948, p. 231).

En efecto, aunque las complejas relaciones entre lavradores, fornecedores (muchos de ellos antiguos senhores de engenho) y usineiros adquirieron características singulares en cada región azucarera de Brasil, el conflicto entre los proveedores de materia prima y los usineiros fue uno de los elementos indubitables que las caracterizaron. Según Lima Sobrinho (1941):

Foram assim surgindo diversos tipos de plantadores, muito diferentes do antigo lavrador de engenho, quanto aos recursos, ao padrão de vida, aos antecedentes e tradições. O lavrador manejava ele próprio a enxada, morando em cabanas humildes. $\mathrm{O}$ fornecedor era um antigo senhor de engenho, com todos os sentimentos dessa classe de dominadores da terra. Aquele conhecia a dependência em que vivia, diante da usina; o fornecedor procurava conservar sua autonomia e queria ser tratado de igual a igual. Era de prever que o usineiro preferisse tratar com os lavradores. Daí os conflitos mais violentos entre as duas classes, o desenvolvimento de uma incompreensão recíproca e cada vez mais séria. (p. 14).

Así, en Pernambuco, los fornecedores nordestinos, sobre los cuales Guillermo Palacios (2012-2013) ha realizado un detallado estudio, en 1929 se decidieron a "organizar-se e entrar em luta com os usineiros sobre os quais obtiveram em 1931 uma vitória com a aprovação de tabelas de fixação de preços da cana" (Azevedo, 1948, p. 230). Un nuevo clima de ideas, alentado por la intensidad de una crisis que el mercado del azúcar había anticipado por lo menos en un lustro y por las demandas de los actores, se constituía entonces en un marco que promovía la consideración de otros parámetros con los que el Estado brasileño llevaría adelante su intervención en la agroindustria cañera, lo que se profundizaría a partir del Estado Novo, cuando se pasó a considerar "a questão do açúcar como um problema nacional e a idéia do dirigismo estatal firma-ser na ideologia dominante" (Gnaccarini, 1972, p. 72). 


\section{LOS ESQUEMAS REGULADORES DE LA DÉCADA DE 1930}

Argentina enfrentó la inédita crisis de los mercados iniciada en la década de 1930 con una tradición de medio siglo en materia de intervención estatal en la agroindustria del azúcar, con una experiencia reguladora de la producción en curso en la provincia de Tucumán y con una institución del Estado central, la Comisión Nacional de Azúcar (en adelante CNA), que podría haber asumido una función rectora en gran escala para conducir la actividad en tiempos de borrasca e incertidumbre. Sin embargo, la CNA tuvo funciones restringidas y no cumplió otro papel que el de un organismo asesor. Por tal razón, en los términos establecidos por la ley de 1928 sólo los productores tucumanos tenían limitada la producción.

Esa limitación estimuló la producción azucarera en Salta y Jujuy, por lo que en 1931 los industriales tucumanos impulsaron un acuerdo privado con los de las provincias vecinas siguiendo algunos de los lineamientos aconsejados por la CNA: asignación de cupos de producción regional; cuotas mensuales de entrega del producto al mercado; cuotas de exportación para liquidar los stocks remanentes de cosechas anteriores, etc. Contra lo esperado, las existencias aumentaron en vez de disminuir, lo que gravitó negativamente en el mercado doméstico. Naturalmente, fue un indicio del fracaso del convenio que sólo se cumplió a medias.

Para hacer frente a la situación, Tucumán propuso en 1932 una nueva ley reguladora de la producción azucarera, que rigió hasta 1935. El objetivo central era aún la reducción gradual de los stocks, pero en función del convenio privado suscrito en 1931, manteniendo la modalidad de obligar a los fabricantes a moler la materia prima de los cañeros más chicos, liquidar el precio de la caña a partir de la cotización del mercado interno y respetar las cuotas sugeridas por la CNA a volcar en el mercado doméstico. Pero el propietario del ingenio con mayor capacidad de molienda de la provincia cuestionó ante la Corte Suprema de Justicia de la Nación la potestad de la administración provincial para regular en el área de la producción e intervenir en la comercialización, lo que fue aceptado por el tribunal tal como lo había hecho en ocasión de las leyes machete de 1902 y 1903 (Schleh, 1939, p. 252).

Durante 1935 y 1936 el gobierno de la provincia cedió ante las presiones de un movilizado gremio cañero, ya que reconoció "derechos de molienda", al punto de que el área cultivada por estos productores excedió los porcentajes fijados por el Laudo Alvear, que establecía un límite a los cañaverales industriales al concederles $56.58 \%$ del área cultivada, mientras que para los cañeros se fijó el 43.42\% restante (en 1935 los productores agrarios molieron 53\% de la materia prima, mientras que a la caña de los ingenios les cupo 47\%, Bravo, 2006, p. 20). Ello incrementó la producción 
tucumana en 1936, situación que promovió una nueva ley reguladora, más estricta, sancionada en 1937 y destinada a regir hasta 1941. La nueva legislación abandonaba el control de la comercialización y se enfocaba en la producción: se limitaba la molienda pero se restablecían los porcentajes sectoriales fijados por el Laudo Alvear, prorrateando los derechos industriales en función de las cuotas oficializadas por la Cámara Gremial de Productores y se contemplaban los derechos de los pequeños cañeros, aunque esta vez con algunas restricciones.

Hasta 1934, las zonas productoras respetaron parcialmente los acuerdos productivos. Pero en 1935, ante la inminencia de una negociación por un nuevo acuerdo, Salta y Jujuy excedieron las respectivas cuotas de producción para exigir mayores porcentajes en la futura distribución. De ese modo, Tucumán debía lidiar con una regulación limitada a su geografía y pautada por un sentido distributivo en lo social, mientras al mismo tiempo debía disputar su cuota de producción con la pujante zona azucarera salto-jujeña, liberada de toda restricción. Tales circunstancias dan cuenta de una situación paradójica en el panorama azucarero argentino: la principal provincia productora limitaba la producción desde hacía casi una década e intentaba ordenar la comercialización a través de acuerdos privados, pero todos esos esfuerzos se malograban por la ausencia de instrumentos legales de alcance nacional como los que reglamentaban otras actividades, tales como la cerealera, la vitivinícola, la yerbatera, etc. Bajo tales circunstancias, el Centro Azucarero solicitó al poder ejecutivo la elevación de un proyecto de ley de regulación de la agroindustria del azúcar.

En 1938, el poder ejecutivo nacional elevó un proyecto de ley que creaba una Junta Reguladora de la Industria Azucarera. ${ }^{6}$ Su función principal sería equilibrar la producción con el consumo doméstico, para lo cual estaría facultada para fijar cupos de producción, autorizaría o prohibiría nuevas plantaciones de caña o de remolacha azucarera, ${ }^{7}$ regularía las entregas de azúcares al mercado interno, incorporaría el régimen contractual establecido en el Laudo Alvear y contemplaba el control de las balanzas de los ingenios a través de la Oficina de Pesas y Medidas del Ministerio de Agricultura.

La iniciativa fue respaldada por el Centro Azucarero Regional del Norte Argentino (representaba a los industriales de Salta y Jujuy), el Centro Azucarero de Tucumán, los gobernadores de las provincias del norte y nú-

${ }^{6}$ Estaría integrada por representantes del Ministerio de Agricultura, del Banco de la Nación, de la Bolsa de Comercio, del Centro Azucarero Argentino, del Centro Azucarero Regional de Tucumán, del Centro Azucarero Regional del Norte, además de delegados de los industriales de las provincias del Litoral y de los productores de materia prima.

${ }^{7}$ Durante la década de 1930 tuvieron lugar experiencias efímeras de producción de azúcar a partir de la remolacha en las provincias de Buenos Aires, San Juan y Entre Ríos. 
cleos de plantadores aislados. Se oponían parcialmente los industriales del Litoral por las cuotas regionales y la Compañía Azucarera Tucumana (propietaria de cinco ingenios tucumanos) por los derechos de industrialización que se le asignaría. Combatían férreamente la ley los plantadores de Tucumán, representados por el Centro Cañero y la Unión Agraria Provincial.

El punto de conflicto eran los derechos de producción de los ingenios, que significaban en la práctica la abolición del sistema de cuota libre para los cañeros que habían contemplado las otras leyes reguladoras tucumanas, además de "atarlos" a determinados ingenios. En el Congreso nacional, los cañeros encontraron activos aliados en los representantes socialistas, quienes se opusieron a las prescripciones sociales de la legislación que preveía una escala de salarios mínimos, acceso gratuito a viviendas de materiales para los trabajadores, la formación de la Caja de Jubilaciones y Pensiones conformadas con aportes de los empleadores y de los trabajadores, asistencia médica obligatoria y gratuita para estos, como también odontológica y oftalmológica de urgencia, argumentando, en palabras del senador Alfredo Palacios, que "aspiraban a una ley más justa, con estudios previos que contemplen en primer término los derechos del consumidor, que es el que sostiene la industria" (Centro Azucarero Argentino, 1938, p. 830).

No obstante la resistencia manifestada, en el Senado la ley fue votada afirmativamente, mientras que en la Cámara de Diputados el desenlace fue adverso. El debate insumió el año 1939 y recibió una amplia cobertura de la prensa de la ciudad de Buenos Aires que cuestionó el proyecto. ${ }^{8}$ En un ambiente caldeado por la crítica el presidente de la nación ordenó al ministro de Agricultura retirar el proyecto regulador del azúcar, esfumándose de ese modo las expectativas de ordenar integralmente la actividad azucarera.

En Brasil, los últimos años de la década de 1920 fueron extremadamente críticos para la industria azucarera, cerrada toda posibilidad de exportar y con un mercado de consumo declinante por la recesión económica. La crisis económica mundial afectaba al principal producto de exportación, el café, lo que minó la posición dominante de la poderosa burguesía paulista y abrió el camino al golpe de Estado respaldado por las elites mineras y gaúchas, cuyo objetivo central consistía en recortar la hegemónica influencia de São Paulo en la política nacional. La revolución, más que imponer una nueva redistribución regional del poder, abrió paso a la acentuación de una política centralista que se desplegó con fuerza luego de la fallida revuelta paulista de 1932 (Boris y Devoto, 2004, p. 254). En ese marco, el gobierno provisional desplegó una serie de políticas activas que incluyeron la actividad cafetalera con la creación del Consejo Nacional

\footnotetext{
${ }^{8}$ El diario La Prensa atacaba al proyecto por anticonstitucional, aunque legislación semejante regía desde hacía varios años para otras actividades productivas.
} 
del Café y la formación de una Comisión de Defensa de la Producción de Azúcar. El objetivo de esta última no era novedoso, restablecer el equilibrio entre producción y consumo a través de la exportación, para lo que se establecía un sistema de tasas para la conformación de un fondo de ayuda, la que se suspendería cuando las cotizaciones en la plaza de Río de Janeiro excedieran cierto nivel. De ese modo, la primera iniciativa reguladora del gobierno de Vargas estuvo limitada a la esfera de la comercialización y fue impulsada a pedido de los industriales de las distintas regiones, no sólo de los nordestinos. ${ }^{9}$

La solución brasileña no siguió el camino de regular la producción para imponer un sesgo distributivo sectorial, como se intentaba hacer en Tucumán, sino que afrontó la regulación del azúcar aprovechando el potencial del alcohol etílico como carburante, perspectiva que a la vez que permitía disponer de un nuevo elemento para estabilizar la producción de azúcar, contribuía a equilibrar la balanza comercial brasileña afectada por las importaciones de gasolina. En consecuencia, una de las grandes innovaciones del gobierno provisional fue incentivar la producción de alcohol carburante en gran escala, mientras que Argentina seguía un camino inverso al desarrollar sus pozos petroleros para potenciar la producción de combustible. De ese modo, el alcohol dejó de ser en Brasil un subproducto del azúcar e involucró a partir de entonces a la agroindustria cañera en la política nacional de combustibles.

En esa dirección fueron clave los decretos nacionales que crearon una comisión de estudios del alcohol, la que estableció las normas técnicas para la producción de alcohol anhidro, además de fijar premios y otros incentivos para la instalación de las primeras plantas de producción del país (Szmrecsányi, 1979, p. 177).

Durante la década de 1930 el azúcar y el alcohol fueron objeto de políticas simultáneas que confluyeron en 1933 con la creación del Instituto do Açucar y Álcool (IAA), concebido como entidad autárquica que asumió la función de dirigir, fomentar y controlar la producción de ambos productos a nivel nacional. Estaba dirigido por una comisión ejecutiva integrada por cuatro representantes del Estado nacional (uno por el Ministerio de Agricultura, otro por el de Hacienda, otro por el de Trabajo, más un delegado

\footnotetext{
${ }^{9}$ El decreto de 7 de diciembre de 1931 que creaba la Comisión de Defensa de la Producción de Azúcar se fundaba en el gran "numero de proprietários de usinas de açúcar em diferentes estados produtores, apelam insistentemente para a intervenção do Governo Federal no sentido de se lhes facilitar lá obtenção, para o produto de suas fábricas, de um justo preço garantidor de razoável remuneração ao trabalho e ao capital" (Cámara dos Deputados. [1931]. Decreto 20.761, 7 de Dezembro de 1931. 19 de fevereiro de 2014, de Cámara dos Deputados. Sitio web: http:// www2.camara.leg.br/legin/fed/decret/1930-1939/decreto-20761-7-dezembro-1931-519440-pub licacaooriginal-1-pe.html).
} 
del Banco de Brasil), a los que se sumaban representantes de los sindicatos de fabricantes de cada Estado cuya producción fuera mayor de 200000 sacos de $60 \mathrm{~kg}$ anuales. Se estipulaba que los distribuidores y comerciantes no integrarían el IAA y se habilitaban delegaciones regionales en los estados de Pernambuco, Alagoas, Sergipe, Bahía, Río de Janeiro, Minas Gerais y São Paulo.

El IAA tenía amplias facultades para asegurar el equilibrio entre la producción y el consumo y determinaba la cantidad de materia prima que se destinaría a la fabricación de alcohol. Estaba obligado a fomentar la fabricación de alcohol anhidro a través de la instalación de refinerías centrales, plantas que serían construidas por sindicatos o cooperativas de fabricantes, aunque, según Szmrecsányi (1979), fueron finalmente construidas y administradas por el propio instituto. Se estipulaba que la entidad debía llevar estadísticas sobre la situación productiva y comercial del azúcar y el alcohol, las que servirían de base para los impuestos aplicados a ambos productos.

Así, la producción de alcohol a través de la caña comenzaría a ser considerada una actividad estratégica para la economía nacional y el IAA asumió amplias funciones en ese campo. Supervisaba los aspectos técnicos de la producción, determinaba las cantidades que debía elaborar cada refinería, adquiría todo el alcohol para abastecer a las compañías importadoras de gasolina y fijaba los precios. Además, instalaba las bombas de abastecimiento de alcohol al público y proporcionaba los técnicos solicitados por las autoridades aduaneras para medir la cantidad de gasolina comprada a granel. También debía verificar los stocks de azúcar, determinar las cuotas de producción para ambos productos y mantenía congelado el número de usinas, ingenios y banguês en funcionamiento.

El Instituto se sostenía con un impuesto de dos réis por litro de gasolina importada, una tasa de 3000 réis por saco de azúcar de $60 \mathrm{~kg}$ de las usinas, junto con un gravamen de $1 \$ 500$ réis por saco de $60 \mathrm{~kg}$ producido por ingenios y banguês. Lo recaudado se aplicaría a las garantías en certificados de azúcares "warranteados" y para amortizar la construcción de destilerías centrales para fabricar alcohol, o como garantía de aplicación de préstamos para los fabricantes o sindicatos que se propusieran instalar refinerías. Estaba obligado a distribuir bonificaciones a cooperativas de industriales que instalaran refinerías centrales de azúcar. Además, el decreto eximía de impuestos a los aparatos destinados a fabricar alcohol anhidro y a los toneles empleados para el transporte de alcohol. Estas medidas de promoción tenían como límite el precio de $\$ 42$ (42000 réis) por saco de azúcar granulado en Río de Janeiro. Si se superaba el precio de \$45 (45 000 réis) el IAA estaba obligado a vender el azúcar en el mercado doméstico.

Como puede observarse, el IAA estaba diseñado con un acentuado criterio de centralización y en ese sentido se asemejaba al fracasado proyecto 
de formación de la Junta Reguladora de la Producción Azucarera argentina, en tanto ostentaba la potestad para regular la producción y el abastecimiento del mercado doméstico, más allá de que el proyecto argentino omitía todo lo relativo al alcohol. Por otro lado, mientras que el proyecto de la Junta Reguladora contemplaba a los trabajadores, a los que se les fijaría un salario mínimo y se les proporcionarían viviendas y asistencia médica, los decretos brasileños no contemplaban la situación social de la actividad. ${ }^{10}$

Puede sugerirse que las diferencias entre ambos sistemas reguladores fueron determinadas por las particulares condiciones sociales y culturales que habían animado ambas actividades azucareras. En Argentina, actores sociales subordinados como los cañeros tucumanos, que habían adquirido durante la década de 1920 suficiente dinamismo e iniciativa para conseguir relaciones contractuales equitativas con los ingenios por medio de la acción colectiva, una década después fueron un obstáculo para la adopción de un esquema de regulación propuesto desde el Ministerio de Agricultura de la Nación; en Brasil, pese a los ásperos choques de intereses entre senhores de engenhos y usineros y a las desconfianzas y resistencias de estos últimos en aceptar la tutela gubernamental, el Estado nacional se mantuvo firme a través de los interventores estatales nombrados por el gobierno provisorio y reguló las relaciones entre los actores. Es decir, los diferentes sectores tuvieron que aceptar el disciplinamiento del complejo azucarero que de algún modo proponía la política centralizada del IAA, la que se profundizó a partir del golpe de Estado de 1937, cuando la cuestión azucarera fue asumida por el Estado Novo como un problema nacional sobre el que era necesario, inapelablemente, intervenir (Szmrecsányi, 1979).

En ese sentido la función "disciplinadora" de las políticas de intervención en el sector sucroalcoholero conducidas desde el IAA ha sido remarcada por Barros Meira en "Uma discussão inacabada..." (2008, pp. 14-15). Es, con otras palabras, la caracterización que propuso Sônia Draibe, para quien lo que se verificó con el IAA fue una "centralização e tendência a supressão de formas duais e fragmentadas do poder, estatização das relações sociais, burocratização e modernização dos aparelhos econômicos, inserção profunda do Estado na vida econômica" (Draibe, 1985, p. 62).

Por el contrario, en Argentina la actividad azucarera, sin un instrumento regulador legal de alcance nacional, siguió un camino errático signado por la competencia entre las diferentes áreas productivas y por la intensificación en Tucumán de la puja distributiva entre cañeros e industriales, situación que debilitó al principal epicentro azucarero del país. Como era

\footnotetext{
${ }^{10}$ Recién a principios de 1941, con el Estatuto da Lavoura Canaviera (Decreto-Ley núm. 3855), algunos derechos de los trabajadores azucareros fueron reconocidos en el marco de un Estado autoritario.
} 
de esperar, el trastorno de la actividad y la caída de los precios era recibido con beneplácito por las industrias del área pampeana que utilizaban el azúcar como insumo, mientras la prensa de Buenos Aires invocaba un "consumidor" en abstracto despojado de sus connotaciones productivas que se "beneficiaba" de los precios de quebranto de la actividad.

\section{REFLEXIONES FINALES}

Este estudio comparativo de las políticas aplicadas en Argentina y Brasil en materia azucarera en el periodo 1880-1930 abordó cuestiones y problemas de diversa naturaleza. A continuación se presenta, a modo de cierre, una serie de reflexiones sobre los mismos, ordenadas en incisos:

a) En ambos países, durante las seis décadas estudiadas, la experiencia de la agroindustria de la caña de azúcar muestra, en primer lugar, que el particular y errático comportamiento del mercado azucarero demandó una amplia gama de intervenciones gubernamentales que ante todo perseguían equilibrar la oferta y la demanda para evitar las debacles de los precios -con las consiguientes caídas de rentabilidad, quebrantos empresarios y sus consecuencias sociales-o el desabastecimiento de los principales centros de consumo. Tales medidas son indicadores de la importancia económica, política y social atribuida por los gobiernos al sector azucarero en un contexto de decidido predominio de la doctrina del laissez-faire en el campo de las ideas económicas.

b) Pese a sus diferentes tradiciones en el rubro y como producto de la evolución del mercado mundial azucarero de fines del siglo XIX y comienzos del Xx, en ambos casos la producción del dulce se sostuvo gracias a la demanda doméstica. En consecuencia, fue clave la protección del mercado interno con la aplicación de aranceles aduaneros proteccionistas. A pesar del uso de esta herramienta y de los niveles de las tarifas adoptadas, las dificultades que ocasionaron las resistencias a su aplicación al desarrollo y estabilidad de la actividad azucarera en los dos países -al contrario de Europa, donde se aplicaban desde hacía casi un siglo- constituye una cuestión que todavía no se ha analizado suficientemente. Lo mismo puede afirmarse para el caso particular de las primas a la exportación, cuya implementación fue obstaculizada por las resoluciones de la Convención de Bruselas que crearon mecanismos multilaterales de imposición del libre comercio (o cuasi libre comercio) enfrentando a Estados Unidos, que continuaba con sus prácticas de restricciones tarifarias y, principalmente, no tarifarias, vinculadas a sus intereses nacionales enmascarados con consideraciones geográficas (tales las excepciones que favorecían las exportaciones de Cuba, Puerto Rico y Filipinas). 
c) En relación con el equilibrio relativo entre el volumen de la producción y el volumen de la demanda doméstica, en un marco muy poco propicio para la colocación de excedentes en el mercado mundial, el crecimiento del mercado interno y de la renta de la población (especialmente en el sureste de Brasil y en el área pampeana argentina) posibilitó en el mediano plazo un sostenido incremento de las producciones locales del dulce.

d) En los dos casos analizados, las iniciativas que propiciaban la intervención estatal fueron demandadas por los propios productores, ya sea solicitando protección frente a los azúcares importados, diversos tipos de apoyo para exportar los excedentes o normativas para ordenar la entrega del producto al mercado. También, en ambos casos, la ecuación política tendía a resolverse en función de la fuerza e influencia política del sector frente a los consumidores y a la industria que demandaba azúcar como insumo.

e) Más allá de estas tendencias que presionaron o condicionaron las políticas públicas como elementos de carácter estructural, la evolución del marco jurídico y la naturaleza de las instituciones (privadas y estatales) que intervinieron directa o indirectamente en el desenvolvimiento del mercado azucarero resultaron de condiciones históricas específicas que no pueden asimilarse entre los dos casos. De todos modos es factible comparar los instrumentos de política económica aplicada al sector con los adoptados para otros sectores de la economía, en forma paradigmática el café en Brasil.

f) La más evidente diferencia de esas condiciones históricas fue la particular conformación de los Estados centrales, las especiales articulaciones de los mismos con la sociedad, la cambiante influencia en el aparato estatal de las clases dominantes y las mudanzas en el bloque de poder. Al respecto, también es evidente el desarrollo desigual del proceso de centralización política y administrativa, que muestra resultados paradójicos. Mientras el Estado central argentino de la década de 1880 (consolidado con el triunfo, precisamente en el año de 1880, de una nueva coalición interelitaria que también integraban empresarios y políticos de las provincias azucareras) demostró efectividad en el armado de un esquema proteccionista de largo alcance que permitió una acelerada modernización y un explosivo desarrollo productivo, el Estado central brasileño (conmovido por una serie de mudanzas entre las que sobresalen la crisis de la monarquía y de la esclavitud) no pudo (o no se planteó) promover políticas que crearan las condiciones para promover una modernización industrial de la misma intensidad y homogeneidad que la que aconteció en Argentina, ni resolver la más acuciante demanda de los productores brasileños, recuperar las posiciones perdidas en el mercado internacional. Sin embargo, medio siglo 
después, en la década de 1930, la situación se presentó de manera inversa. Mientras Brasil dio inicio a un proceso de fuerte intervención que se aplicó por décadas en toda su extensa geografía y en el cual el Instituto do Açúcar e do Álcool desempeñó un protagonismo casi excluyente, en Argentina el Estado nacional renunció a plantear un ordenamiento que a la vez que alentara el desarrollo azucarero moderara los conflictos de intereses que se planteaban entre industriales, los productores de materia prima y los sectores interesados en disponer de "azúcar barato" (no está de más apuntar, marginalmente, que entre 1945 y 1955 la nueva coalición social que expresó el peronismo intentó ordenar de manera integral la actividad a escala nacional con un esquema que privilegiaba la redistribución del ingreso en beneficio de los asalariados y los minifundistas cañeros).

g) Sin duda, la absoluta dependencia energética de Brasil fue el principal estímulo para la promoción del alcohol carburante, lo que convirtió al IAA, además de en un órgano de ordenamiento del sector, en un centro promotor de investigaciones tecnológicas, aunque como se ha anotado en el texto el decisivo impulso a la producción del alcohol carburante llegó con el Estado Novo. Por su parte, Argentina escogió otro camino en el rubro, desestimando la utilización de la caña de azúcar para la producción de combustibles y apostando a las perspectivas que ofrecía la explotación de los recursos petrolíferos nacionales, sector en donde se concentraron los esfuerzos para avanzar en el autoabastecimiento energético.

h) En los dos países el papel económico y político de las elites involucradas en la producción azucarera ocupó cierta centralidad, entre aquellas elites se destacaron las de Pernambuco y Tucumán. Sin embargo, en los dos casos la emergencia de áreas que gracias a la disponibilidad de recursos las posicionaban muy favorablemente en un esquema agroexportador (café en São Paulo, cereales y carnes en la región pampeana) debilitaron progresivamente el peso económico y político de las mismas, dejándolas como estrellas menores en el firmamento de las clases dominantes. Sin duda esa pérdida de influencia relativa repercutió negativamente en las posibilidades de éxito de las iniciativas que esos sectores se dispusieron llevar adelante.

i) Como ha quedado claro, en ninguno de los dos países el azúcar constituyó o articuló la principal actividad económica, como fue, por ejemplo, el caso de Cuba. Para las elites azucareras esta circunstancia implicó la necesidad de encarar complicadas negociaciones y concertar complejas alianzas con otros sectores sociales con la finalidad de llegar a acuerdos, en particular en el ámbito parlamentario. No obstante, el diseño y ejecución de las ingenierías políticas y sociales pensadas para valorizar e impulsar de manera sostenida la producción enfrentaron no pocas dificultades.

j) Las diferencias regionales también pueden contabilizarse como una característica compartida por ambos países, aunque su diversidad haya 
sido mayor en Brasil que en Argentina. Otra vez aquí es necesario destacar el papel que cumplieron Tucumán y Pernambuco, estados que por constituir por largo periodo el epicentro productivo del dulce fueron los que más énfasis pusieron en implantar regulaciones y que hasta se aventuraron a desarrollar experiencias de ese tipo en sus respectivas jurisdicciones territoriales.

k) Quizá por una de las razones enunciadas, la mayor centralización política resultante del arreglo institucional de 1880, la protección aduanera fue mucho más visible o notoria en Argentina que en Brasil. Es posible que los álgidos debates en el Congreso nacional sobre la materia y la repercusión que los mismos tenían en la prensa de la ciudad de Buenos Aires -notoriamente favorable a esquemas librecambistas- hayan hecho posible esta percepción. En Brasil también hubo importantes debates (por ejemplo, los que tuvieron lugar en los congresos nacionales de agricultura y otras conferencias de este tipo), pero su repercusión pública fue mucho mayor en los estados del Nordeste que en los del sureste.

l) Las semejanzas y divergencias posibles de identificar en esos debates son también sugerentes. En Argentina, a partir de las discusiones en torno a las leyes de aduana de 1894, el principio de "los derechos del consumidor" fue el argumento central esgrimido contra los aranceles a la importación de azúcares extranjeros (que se consideraban exageradamente altos) y uno de los fundamentos de lo que se dio en llamar "proteccionismo racional". Del mismo modo, en Brasil, en el caso de las discusiones que tuvieron lugar entre 1918 y mediados de la década de 1920, la necesidad de no alimentar la inflación con el incremento de los precios de los productos de "primera necesidad" (entre los que se ubicaba el azúcar) fue un argumento político recurrente.

m) Menor correspondencia puede establecerse en el tratamiento de las connotaciones que sobre la distribución del ingreso tenían -o podrían tener- las diversas formas del intervencionismo estatal en discusión. Mientras en Argentina, por ejemplo, las controversias sobre las modalidades regulatorias en discusión incorporaron la problemática ya en la década de 1920, la "cuestión social" cobró envergadura en Brasil recién con el Estatuto de Lavoura Canavieira de 1941.

n) No obstante esa afirmación precedente, es indudable que la conflictividad social y las tensiones interregionales fueron algunos de los elementos decisivos que alentaron en Brasil la deriva hacia una intervención estatal más radical. En ese sentido hay que destacar el ánimo de conciliar los intereses de clase, los del agro con los de la industria, los del Nordeste con la cada día más pujante región azucarera del centro-sur y los de los productores con los de los consumidores, muy explícito en los primeros 
ensayos regulacionistas del régimen de Getúlio Vargas, objetivos enmarcados en un innegable programa de disciplinamiento social.

\section{LISTA DE REFERENCIAS}

Azevedo, F. DE (1948). Canaviais e engenhos na vida política do Brasil. Río de Janeiro: Instituto do Açúcar e do Álcool.

BALÁN, J. (1978). Una cuestión regional en la Argentina: burguesías provinciales y mercado nacional en el desarrollo agroexportador. Desarrollo Económico, 69, 49-87.

Barros Meira, R. (2007). Banguês, engenhos centrais e usinas: o desenvolvimento da economia açucareira em São Paulo e a sua correlação com as políticas estatais (1875-1941) (Tesis inédita de maestria). Universidade de São Paulo, São Paulo.

Barros MeIrA, R. (2008). Uma discussão inacabada: a modernização e o desenvolvimento da agroindústria sucroalcooleira no Brasil: 1875-1945. Revista Ágora, 8, 1-22.

Barros Meira, R. (2013). O prêmio imediato ou o suicídio: as políticas de valorização do açúcar na Primeira República. Trabajo inédito presentado en IV Seminário Internacional de História do Açúcar: Patrimônio, Economia e Sociedade, Santos.

Barros Meira, R. (2014). São os "Centrales" que distinguem o açúcar: O encantamento dos produtores de açúcar brasileiros pelos engenhos centrais cubanos. Travesía, 16, 5-27.

Bittencourt, G. (1999). Açúcar e legislação. A política brasileira das usinas centrais e sua influência no Espírito Santo (1870-1920). Vitória: Edit.

Boris, F. y Devoto, F. (2004). Brasil e Argentina. Um ensaio de história comparada (18502002). São Paulo: Editora 34.

Brasil, Agencia Nacional (1939). O açúcar sob o governo Getúlio Vargas. Río de Janeiro: Direcção Nacional de Propaganda.

Bravo, M. C. (1991). Las Leyes Machete y la ruptura del Frente Azucarero Tucumano. En D. CAMPI (comp.), Estudios sobre la historia de la industria azucarera argentina (pp. 97-138). San Salvador de Jujuy: Universidad Nacional de Jujuy/Universidad Nacional de Tucumán.

Bravo, M. C. (2000). Liberales, socialistas, Iglesia y patrones frente a la situación de los trabajadores en Tucumán (segunda mitad de siglo XIX). En J. SuRIANO (comp.), La cuestión social en Argentina 1870-1943 (pp. 31-61). Buenos Aires: La Colmena.

Bravo, M. C. (2006). Regulaciones en la industria azucarera. En A. VIERA (coord.), História do açúcar, fiscalidade, metrologia, vida material e patrimonio (pp. 124-152). Funchal: Centro de Estudos de História do Atlântico.

Bravo, M. C. (2009). Campesinos, azúcar y política: cañeros, acción corporativa y vida política en Tucumán (1895-1930). Rosario: Prohistoria.

Brollo, F. (2009). Co-evolução da mudança tecnológica e institucional em sistemas de inovação: análise histórica da indústria de álcool combustível no Brasil (Tesis inédita de doctorado). Universidade Federal do Rio de Janeiro, Río de Janeiro. 
Campi, D. y Lagos, M. (1995). Auge azucarero y mercado de trabajo en el noroeste Argentino. En J. Silva, J. C. Grosso y C. Yuste (comps.), Circuitos mercantiles y mercados en Latinoamérica. Siglos XVIII y XIX (pp. 442-499). México: Instituto de Investigaciones Dr. José María Luis Mora/Universidad Nacional Autónoma de México.

Centro Azuchrero Argentino (1938). La Industria Azucarera, 540.

CoRTÉs Conde, R. (1979). El progreso argentino, 1880-1914. Buenos Aires: Sudamericana. Draibe, S. (1985). Rumos e metamorfoses: Estado e industrialização no Brasil (1930-1960). Río de Janeiro: Paz e Terra.

Guimarães, C. G. (2013). O Instituto do Açúcar e do Álcool (IAA) e o projeto corporativo da indústria do álcool-motor no primeiro governo Vargas (1930-1945). Trabajo inédito. Universidade Federal Fluminense, Brasil.

GNACCARINI, J. C. (1972). Estado, ideologia e açao empresarial na agroindústria açucareira do estado de São Paulo (Tesis inédita de doctorado). Universidade de São Paulo, São Paulo.

GuY, D. (1981). Política azucarera argentina. Tucumán y la generación del 80. San Miguel de Tucumán: Fundación Banco Comercial del Norte.

Kindgard, A. y CAMPI, D. (2006). La política azucarera argentina en las décadas de 1920 y 1930 y la cuestión de la justicia distributiva. En H. CRESPO (coord.), El azúcar en América Latina y el Caribe. Cambio tecnológico, trabajo, mercado mundial y economía azucarera. Perspectiva histórica y problemas actuales (pp. 337-403). México: Senado de la República.

Lenis, M. (2009). Estrategias corporativas y discurso empresario: el Centro Azucarero Argentino, 1894-1923 (Tesis inédita de doctorado). Universidad Nacional de Tucumán, San Miguel de Tucumán.

LIMA, B. (1941). Problemas económicos e sociais da lavoura canavieira. Río de Janeiro: IAA.

Moura Filho, H. (2012-2013). Os países latino americanos e a convenção açucareira de Bruxelas de 1902. Travesía, 14-15, 221-246.

Palacios, G. (2012-2013). Os plantadores de cana de Pernambuco na primeira metade do século Xx: nascimento, crise e consolidação de uma 'classe' agrária. Travesía, 14-15, 161-219.

PuCCI, R. (1998). Crecimiento, mercados y políticas en el azúcar: una perspectiva comparativa entre el caso argentino y otras economías latinoamericanas. Trabajo inédito presentado en XVI Jornadas de la Asociación Argentina de Historia Económica, Universidad Nacional de Quilmes, Quilmes.

Ribeiro, A. (2000). Um século de economia açucareira. Evolução da moderna agroindústria do açúcar em São Paulo, de 1877 a 1970. São Paulo: Clíper Editora.

SÁnchez Román, J. A. (2005). La dulce crisis: Estado, empresarios e industria azucarera en Tucumán, 1853-1914. Madrid: Diputación de Sevilla/Universidad de Sevilla/Consejo Superior de Investigaciones Científicas.

Schleh, E. (1939). Compilación legal del azúcar (vol. IV). Buenos Aires: Centro Azucarero Argentino. 
SZMrecsáNYI, T. (1979). O planejamento da agroindustria canavieira do Brasil (1930-1975). São Paulo: Hucitec/Universidade de Campinas.

Szmrecsányi, T. y Ramos, P. (2005). Agroindústria canavieira e política económica no século Xx. Trabajo inédito presentado en II Seminário de História do Açúcar, Museo Paulista, Itu.

Szmrecsányi, T. y Veiga, A. DE A. (1999). O ressurgimento da lavoura canavieira em São Paulo na Primeira República, 1890-1930. Travesía, 2, 67-81. 